\title{
Status of the Ganges river dolphin or shushuk Platanista gangetica in Kaptai Lake and the southern rivers of Bangladesh
}

\author{
Brian D. Smith, Benazir Ahmed, Muhammad Edrise Ali and Gill Braulik
}

\begin{abstract}
Surveys for shushuks Platanista gangetica were conducted during January to April 1999 in Kaptai Lake and the southern rivers of Bangladesh. A population of at least 125 dolphins was recorded in the Karnaphuli and Sangu rivers and connecting canal. The overall encounter rate- was 0.76 dolphins per $\mathrm{km}$. Density was highest in the lower reaches of the Sangu, where we recorded 1.36 dolphins per $\mathrm{km}$. These rates are fairly high when compared with other areas of shushuk distribution. Dolphin movements in the Sikalbaha-Chandkhali Canal were consistent with it being used as a corridor for migration and dispersal between the Karnaphuli and Sangu. Shushuks were also sighted in marine waters of the Karnaphuli and Sangu river mouths, adding credibility to the hypothesis that dolphins move along the coast between the GangesBrahmaputra-Meghna and Karnaphuli-Sangu systems, perhaps during the monsoon when freshwater plumes
\end{abstract}

extend into the Bay of Bengal. No dolphins were observed in Kaptai Lake, a dam-created reservoir of the upper Karnaphuli, despite reports of occasional sightings by local fishermen. No shushuks were observed in the Bagkhali and Matamuhuri rivers, possibly because of seasonal-closure dams present near the mouths of both rivers. The main threats to dolphin survival in the Karnaphuli-Sangu system are probably accidental entanglement in monofilament gillnets, bioaccumulation of persistent contaminants and possibly collisions with motorized vessels and a decline in prey as a result of over fishing. The most significant conservation measure that could be taken would be to establish a protected area for dolphins in the Sangu River below the Dohazari Bridge.

Keywords Bangladesh, Kaptai, Karnaphuli, Orcaella, Platanista, river dolphins.

\section{Introduction}

Platanista gangetica or shushuk, as the dolphin is called in Bangladesh, is an endangered river dolphin (International Union of Conservation of Nature (IUCN), 1996) distributed primarily in the Ganges-Brahmaputra-Meghna river system of Nepal, India and Bangladesh (Fig. 1; Mohan et al., 1997; Smith et al., 1998; Sinha et al., 2000) but also in the comparatively much smaller Karnaphuli and Sangu rivers of southern Bangladesh (Fig. 2; Reeves et al., 1993; Ahmed, 2000). Although different watersheds feed the Karnaphuli and Sangu, the SikalbahaChandkhali Canal connects them in their lower reaches. Both the rivers and the canal are, hereafter, referred to as the Karnaphuli-Sangu complex. Shushuks have also

Brian D. Smith (corresponding author) Aquatic Biodiversity Associates, PO Box 3479 Eureka California 95502, USA.

E-mail: orcaella@northcoast.com

Benazir Ahmed Department of Zoology, University of Chittagong, Chittagong, Bangladesh

Muhammad Edrise Ali Department of Chemistry, Chittagong College, Chittagong. Bangladesh

Gill Braulik Ocean Park Conservation Foundation, Ocean Park, Aberdeen, Hong Kong

Revised manuscript accepted for publication 9 August 2000 been infrequently reported from Kaptai Lake, one of the largest reservoirs in Asia, created in 1961 by the construction of a high dam about $80 \mathrm{~km}$ upstream of the Karnaphuli river mouth.

The first record of shushuks in the Karnaphuli River (and Halda tributary) was a range map contained in Anderson (1879). The next reference was a report that shushuks were frequently observed close to the mouth of the Karnaphuli at low and high tides (Pelletier \& Pelletier, 1986). A photograph of a shushuk specimen, which was reportedly caught in the vicinity of Chittagong in June 1978, probably from the Halda River (Aminul Haque, pers. comm.), was shown in Reeves \& Brownell (1989). Reliable sources reported sighting two dolphins in the western arm of Kaptai Lake in July 1992 (Reeves et al., 1993). A dead shushuk was found floating in the western arm of Kaptai Lake near Rangamati with a fishing rope twisted around its body in October 1994 (Ahmed, 2000). The existence of a photograph of a shushuk reportedly found stranded and killed by villagers along the Sangu River, was documented in Reeves et al. (1993).

The need for a systematic survey of shushuks in Kaptai Lake and the southern rivers of Bangladesh was recognized by the Asian River Dolphin Committee during meetings in 1994 (Reeves \& Leatherwood, 1995) 


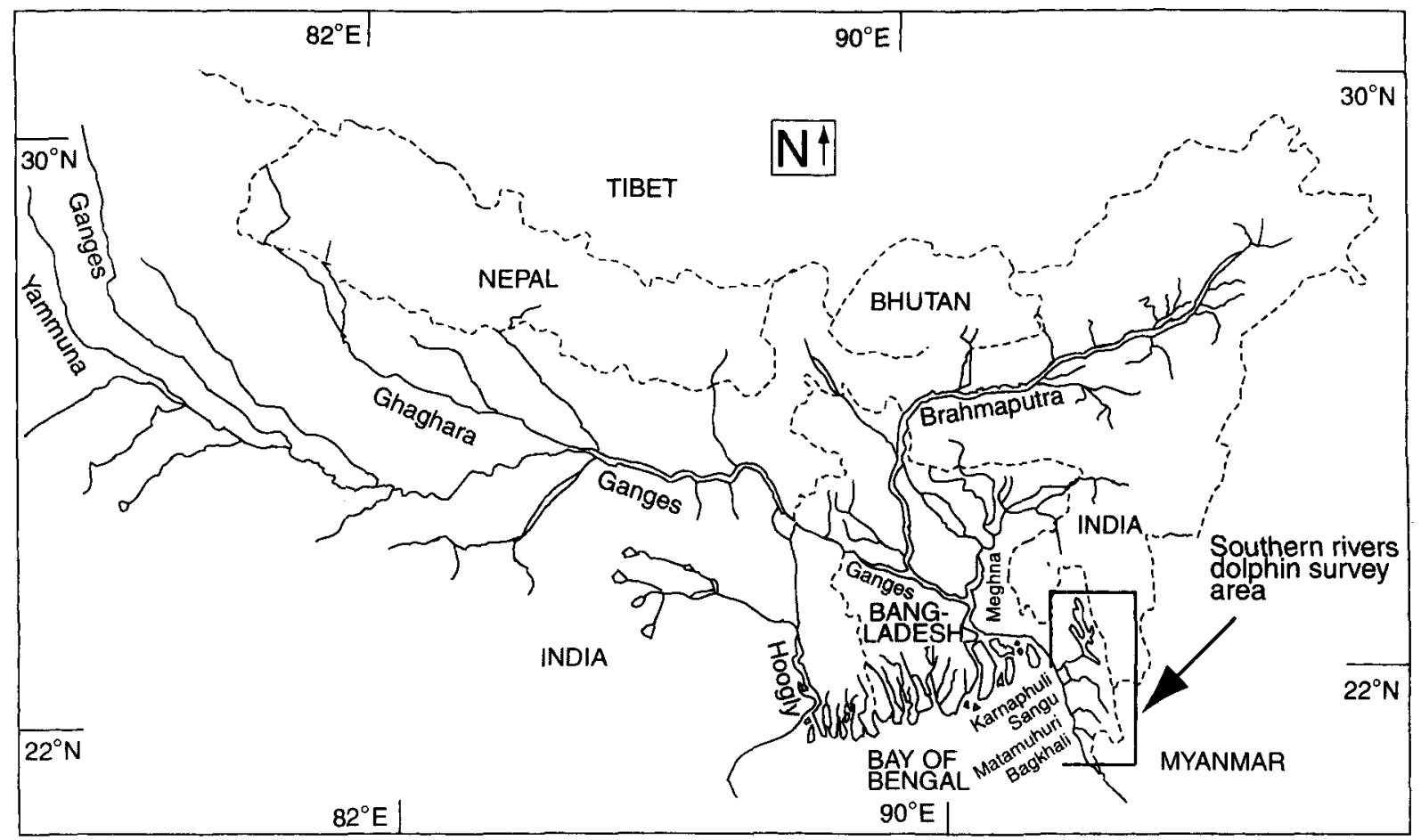

Fig. 1 The Ganges-Brahmaputra-Meghna and Karnaphuli-Sangu river systems in Nepal, India and Bangladesh.

and 1997 (Smith \& Reeves, 2000a). Casual surveys conducted in April and May 1998 (see Ahmed, 2000) revealed a more widespread and abundant population than perhaps expected. The surveys also highlighted questions, whether dolphins move between the Sangu and Karnaphuli rivers via the Sikalbaha-Chandkhali Canal, and among the lower Meghna, Karnaphuli, Sangu and possibly Matamuhuri and Bagkhali rivers (Fig. 3) via coastal waters, maybe during the flood season when the rivers' freshwater plumes extend into the Bay of Bengal.

\section{Methods}

We conducted visual surveys for shushuks in Kaptai Lake, the Sikalbaha-Chandkhali Canal, and the Karnaphuli (and Halda tributary), Sangu, Matamuhuri and Bagkhali rivers (southern rivers dolphin survey area on Figs 1-3, respectively) using local motorized and oarpowered boats during January to April 1999. The survey was intentionally conducted during the low water season when the river is accessible and dolphins are more concentrated and therefore more likely to be seen. In January 1999, we also conducted a survey along the coast from Cox's Bazaar to Chittagong searching for shushuks and marine cetaceans.

We generally followed the survey procedures described in Smith \& Reeves (2000b). Two or three primary observers searched for dolphins forward of the bow whereas another observer, if available, searched towards the rear. The eye height of observers above the waterline was 2-3 m, except during the Bagkhali and Matamuhuri surveys and Halda survey between Nazirhat Bazaar and Sattar Ghat, when it was approximately $1 \mathrm{~m}$. In wide channels - defined as being wide enough so that dolphins surfacing within the observers' field of view could easily be missed - we followed a search path $50-100 \mathrm{~m}$ offshore of the riverbank and arbitrarily alternated between sides. In narrow channels, we followed a search path in the approximate centre of the river channel, except when shallow water required us to follow the thalweg (path connecting the deepest points in a series of cross-sections). We maintained a record of search effort, including information on sighting conditions, channel type and width, shoreline features, human activities, distance covered and the amount of time spent searching for dolphins. During dolphin sightings, we recorded best, high and low estimates of group size and estimated the distance dolphins were located from the shore. We defined a dolphin group as the group of animals located in the zone of hydrological influence (i.e. river reach) where the sighting was made. Although we used standardized criteria for defining river reaches (see Frissel et al., 1986; Kellerhalls \& Church, 1989) and attempted to be as consistent as possible, the definition of reach borders 
Fig. 2 Kaptai Lake, Karnaphuli and Sangu rivers and the Sikalbaha-Chandkhali Canal.

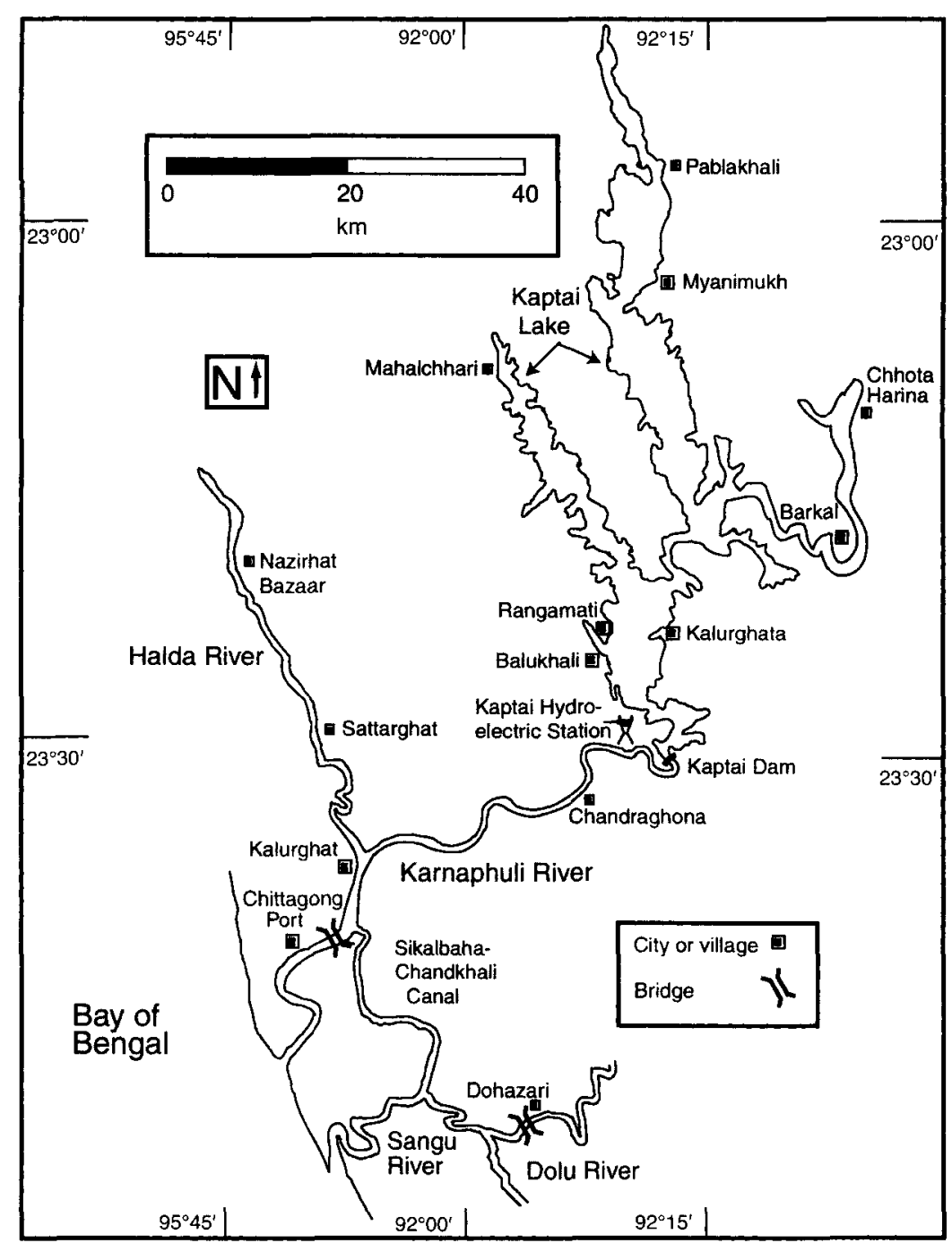

invariably required some subjective judgement in the field. We considered it important, however, for the focus of the sighting to be on the animal group vs. individuals. This allowed us to evaluate abundance in terms of a range of estimates, rather than an absolute count, which would not reflect the inherent uncertainty about the actual number of animals present (Smith \& Reeves, 2000b). We avoided double counts by maintaining close communication among observers and, for some sightings, using a zero for our low, or even best, group size estimates, if there was a possibility that the animals had already been counted. We calculated an encounter rate for each waterway as the sum of best estimates for all sightings made by the primary observers divided by the total distance surveyed. This sum, plus the number of animals sighted by the rear observer that were missed by the primary observers, was used to estimate the minimum abundance of dolphins in each waterway.

\section{Results}

No dolphins were observed during our survey of Kaptai Lake. The coverage was fairly widespread and included transect lines, all starting from Rangamati, in the western arm to Mahalchhari, in the eastern arm to Pablakhali and in the far eastern minor arm to Chhota Harina. Dolphins were recorded in fairly high densities during surveys of the entire Karnaphuli-Sangu complex (125 dolphins in total; 0.76 dolphins per $\mathrm{km}$ ), especially in the Sangu below the Dohazari Bridge (59 dolphins in total; 1.36 dolphins per $\mathrm{km}$; Table 1). No dolphins were observed in the Matamuhuri and Bagkhali rivers, but we received conflicting reports from local fishermen that they occurred far upstream in the Matamuhuri River during the monsoon season and in the mouth of the Bagkhali during the low-water season (Table 2).

On 31 January, we surveyed $94.0 \mathrm{~km}$ along the coast between Cox's Bazaar and Chittagong, generally 


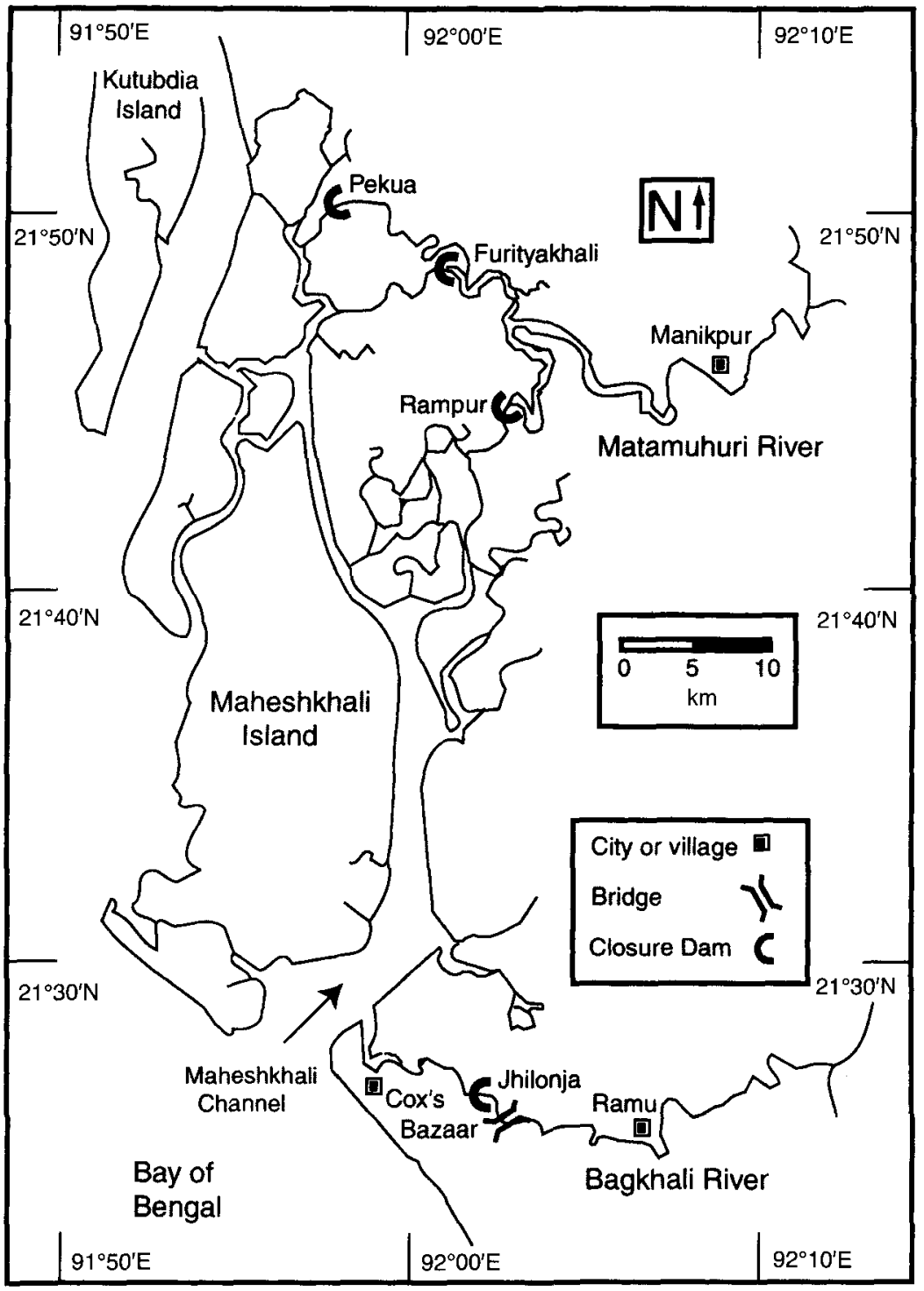

Fig. 3 The Bagkhali and Matamuhuri rivers showing locations of closure dams. remaining $1-3 \mathrm{~km}$ offshore. We had two sightings of Irrawaddy dolphins Orcaella brevirostris for a total of 4-6 dolphins. Both sightings were located less than $2 \mathrm{~km}$ offshore of mangrove forests and in the vicinity of bottom-set gillnets. We also recovered the floating carcass of a neonate Irrawaddy dolphin. Visible foetal folds and a dorsal fin that was not yet fully erect indicated its young age. The total length of the dolphin, measured from the anterior end of the mouth to the median notch of the flukes was $105 \mathrm{~cm}$.

\section{Discussion}

\section{Distribution and abundance}

We are concerned about the absence of dolphin sightings in Kaptai Lake. Sighting rates were expected to be low because of the vastly increased surface area of the reservoir relative to the river before dam construction. We believe, however, that if the lake contained a viable population, our extensive survey effort should have yielded at least a few sightings.

If shushuks were able to move freely between the Karnaphuli and Sangu rivers via the Sikalbaha-Chandkhali Canal, the increase in aggregate habitat would provide a greater range of environmental conditions for the dolphins to utilize during different hydrological and tidal conditions. It would also provide greater options for refuge during local anthropogenical disturbances. Sufficient water was present during a significant portion of the tidal cycle to permit dolphin movement through the canal. Observations of shushuks clumped in relatively high densities at both ends of the canal during low tide but distributed more continuously during high tide 
suggest that the canal may be used as a corridor for migration and dispersal. We therefore tentatively consider dolphins in the Karnaphuli and Sangu to constitute a single population. A caveat is that no dolphins were observed in $7.4 \mathrm{~km}$ of the middle portion of the canal during all three surveys. Although this lends a degree of uncertainty to our reasoning and points to the importance of further investigation, one of the authors (B.D.S.) has observed shushuks occupying a shallower and narrower channel in the Kulsi River, a small tributary of the Brahmaputra in India (see also Mohan et al., 1998).

The minimum abundance-estimate for the Karnaphuli-Sangu complex (125 dolphins) was based on the sum of best estimates for the January surveys of both rivers ( 92 dolphins seen by primary observers plus seven seen by the rear observer), the sum of estimates of the first survey of the Sikalbaha-Chandkhali Canal (18 dolphins), and the number of animals observed during the survey of the Halda River in February (four dolphins seen by the primary observer and four seen by the rear observer). Due to biases associated with estimating river dolphin abundance from direct counts (e.g. long submergence times, cryptic surfacings and observer inattention or focus on locations different from where dolphins are surfacing (see Smith \& Reeves, 2000b), we believe that the actual number of dolphins in the Karnaphuli-Sangu complex could be substantially higher.

The rear observer observed 10-32 per cent of the total number of dolphins sighted. This does not include the Halda survey, where we had only a single primary observer and used a small rowboat for a large portion of the survey. In this narrow channel, the rear observer saw 50 per cent of the total number of dolphins sighted. Dolphins were also occasionally seen after survey effort was suspended but then not observed by the rear or primary observers when we resumed search effort a few minutes later. This indicates that direct counts underestimate absolute abundance, which was expected considering sighting biases. We believe, however, that our estimates of minimum and relative abundance provide important information for assessing the viability of the Karnaphuli-Sangu population and serve as baseline data for detecting long-term abundance trends (see Taylor \& Gerrodette, 1993), however, for a discussion of problems with detecting population trends in small populations). Additional data from rear observer sightings may allow for a correction factor to be calculated to reduce the negative bias of minimum estimates obtained when a rear observer is not available (see Smith \& Reeves, 2000b).

The encounter rates of 0.76 dolphins per $\mathrm{km}$ in the Karnaphuli-Sangu complex (calculated from the sum of best estimates of primary observer sightings for the January surveys of the Karnaphuli and Sangu rivers and the first survey of the Sikalbaha-Chandkhali Canal divided by the total survey range where dolphins were observed) and 1.36 dolphins per $\mathrm{km}$ in the lower Sangu are comparable or substantially higher than those recorded in other areas of shushuk distribution. A downstream survey of the Vikramshila Gangetic Dolphin Sanctuary in the middle reaches of the Ganges mainstem $(60.3 \mathrm{~km}$ covered) recorded 0.81 dolphins per $\mathrm{km}$ (Sinha et al., 2000). Encounter rates have been reported as generally lower in other river segments, such as 0.24 dolphins per $\mathrm{km}$ in the middle reaches of the Jamuna (Brahmaputra) River $(89.6 \mathrm{~km}$ surveyed) and 0.30 dolphins per $\mathrm{km}$ in the Kalni-Kushiyara River $(113.0 \mathrm{~km}$ surveyed) - rates recalculated from sightings per $\mathrm{km}$ reported in Smith et al. (1998). The Sangu River downstream of the Dohazari Bridge supported the highest density of dolphins and, to the best of the authors' knowledge, the encounter rate recorded in this segment is the highest documented for the species. The lower Sangu is the most undisturbed area within the range of dolphins in the KarnaphuliSangu complex and may serve as an important refuge from environmental disturbances, such as industrial pollution and high vessel traffic, in the lower Karnaphuli.

The absence of dolphin sightings in the Matamuhuri and Bagkhali rivers may have been a result of the construction of seasonal closure dams, which block all freshwater outlets during the dry season. Reports of dolphins occurring upstream of the dam sites in the Matamuhuri River during the monsoon and the recovery of a lower jaw of a shushuk, reportedly caught below the Bagkhali Rubber Dam in January, indicate that shushuks may have historically used these rivers during the dry season, and may still use them during the flood season. Assuming that shushuks have the ability and motivation to disperse along the coast of southern Bangladesh, the blockage of the Matamuhuri and Bagkhali rivers during the dry season would then represent a reduction in freshwater habitat.

Sightings of shushuks in marine waters of the Karnaphuli and Sangu river mouths indicate that they can tolerate saline environments for at least a short period. The limitation of their range to freshwater bodies, therefore, may be better explained by ecological adaptations and inter-specific competition, possibly with Irrawaddy dolphins, rather than physiological requirements. These observations also imply that shushuks may be able to move along the coast of the Bay of Bengal among the lower Meghna River, Karnaphuli-Sangu complex, and Matamuhuri and Bagkhali rivers. 
B. D. Smith et al.

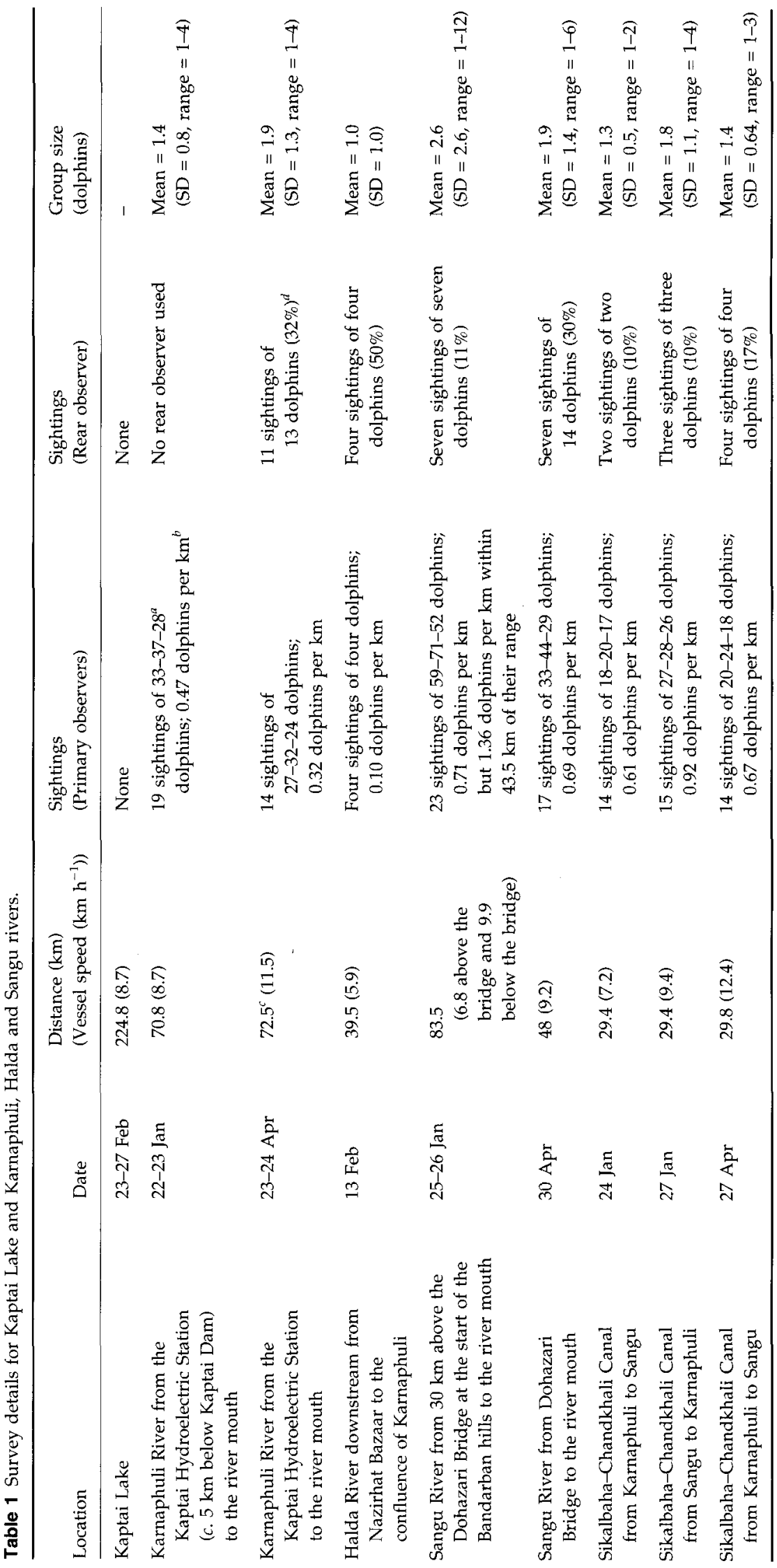

(c) $2001 \mathrm{FFI}$, Oryx, 35(1), 61-72 


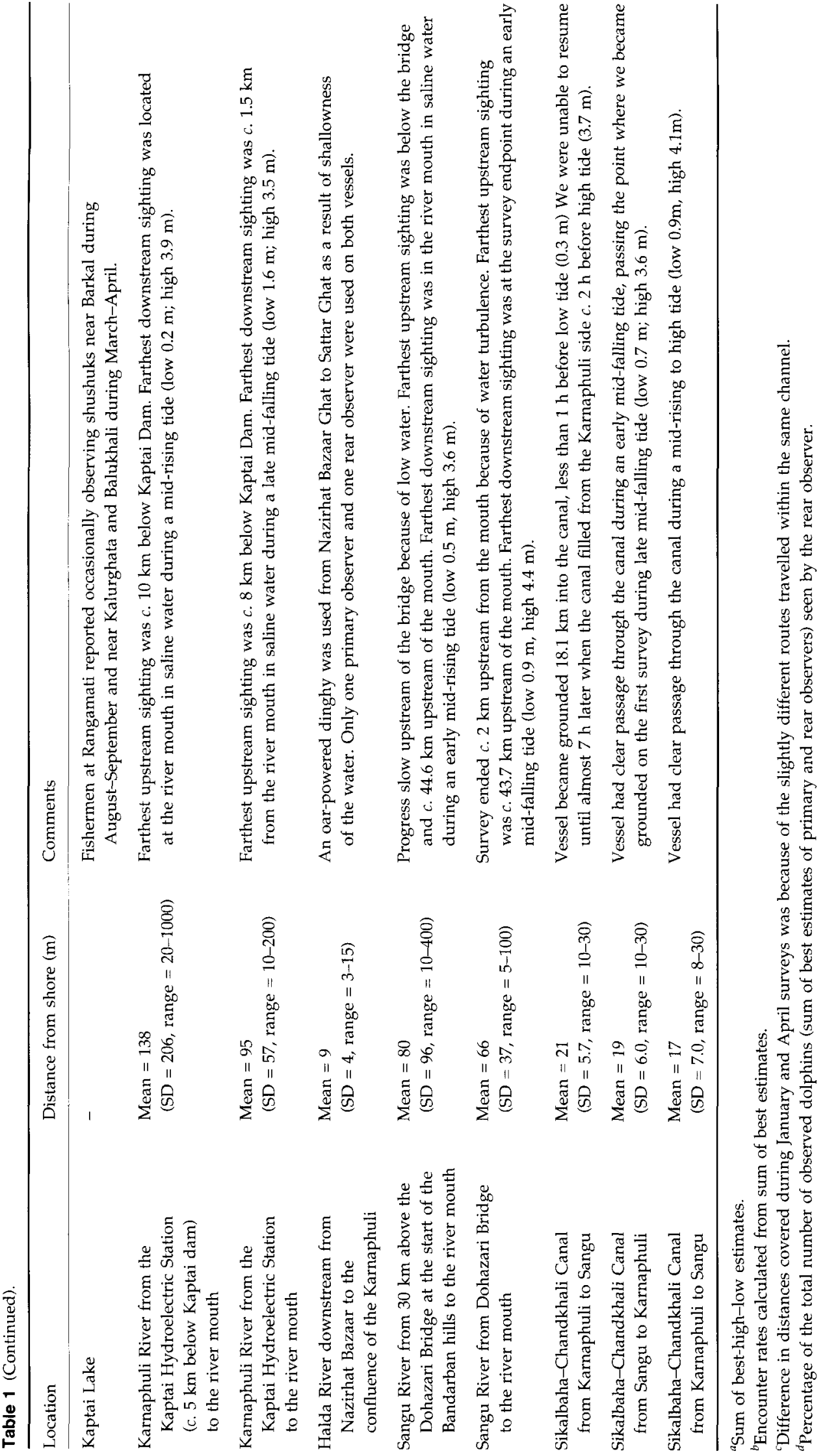




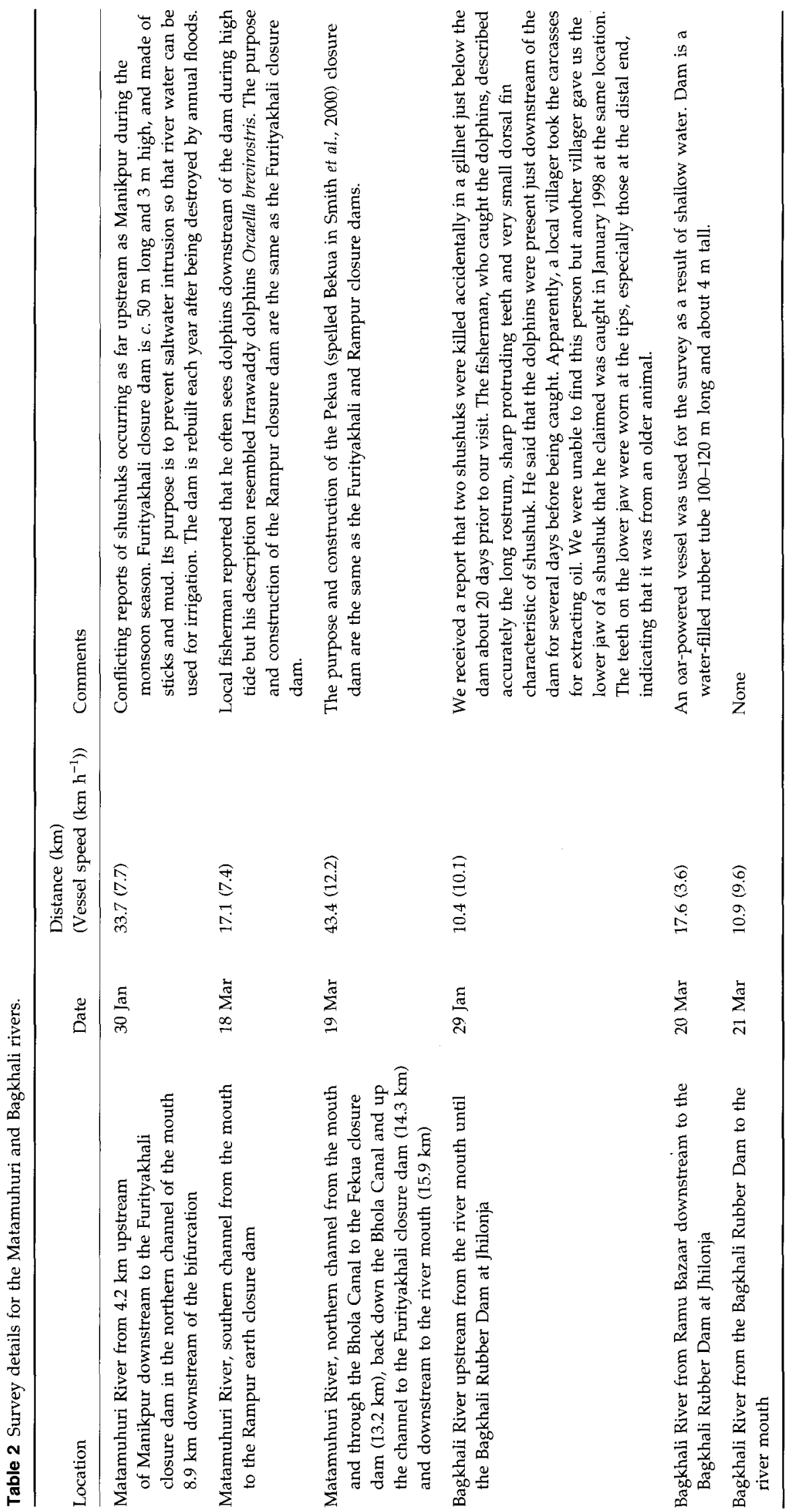

(c) $2001 \mathrm{FFI}$, Oryx $, 35(1), 61-72$ 


\section{Habitat preferences}

Shushuk habitat is generally described as consisting of eddy counter-currents located downstream of channel convergences and sharp meanders and upstream and downstream of mid-channel islands (Smith, 1993; Smith et al., 1998; Smith \& Reeves, 2000c). It has been suggested that the affinity of shushuks for counter-currents declines in large channels where current velocity is reduced and eddy boundaries are ill-defined (Smith et al., 1998). Shushuks in the Sangu and Karnaphuli appeared to be attracted to counter-currents when current velocity was high, which depended on the tidal cycle, but became more uniformly dispersed during slack water. In April 1998, during a casual survey, two of the authors (B.D.S. and B.A.) observed a very large group of about 20 shushuks in a counter-current downstream of a sharp meander in the lower reaches of Karnaphuli during a rapidly falling tide. Dolphins were absent from this area during our first Karnaphuli survey at mid-rising tide and present in groups of five during the second survey at mid-falling tide. Dolphins were also observed in the tidal lee of anchored vessels at Chittagong Port. Tidal and river flow conditions, including the hydrological modifications caused by Kaptai dam and the trans-flow between the Karnaphuli and Sangu via the Sikalbaha-Chandkhali Canal, create a complex aquatic environment. Dolphin distribution within the Karnaphuli-Sangu complex probably reflects the patchy and dynamic distribution of prey and hydraulic refuge.

\section{Threats}

Similar to all cetaceans, shushuks are vulnerable to accidental entanglement in monofilament gillnets. According to local fishermen in the Brahmaputra River near Sirajganj, Bangladesh, accidental entanglements in monofilament gillnets are their primary source of dolphin oil, which is used as a fish attractant (see Motwani \& Srivastava, 1961) and accounts for mortality in the middle reaches of the river that was roughly estimated to be 90-160 dolphins each year (Smith et al., 1998). Monofilament gillnets (current-jahls) with a stretched mesh-size of less than $4.5 \mathrm{~cm}$ are prohibited in Bangladesh, but their use is increasing (Liquat Ali, personal communication). Shushuks have been reported to be caught in jam jahls, rectangular nets with an 8-10-cm mesh size used to catch large economically valuable fish in counter-currents (Bangladesh Water Development Board, 1994). Both these types of nets were observed being used in the Karnaphuli, especially near the canal confluence and in the large counter-current close to the mouth, and in the Sangu, near the Dolu
River and canal confluences. Mosquito nets were commonly observed set in shallow channels to catch fish fry and crustacean larvae for aquaculture purposes. These nets are particularly destructive when set during breeding migrations and early growth of fishes and crustaceans.

Concentrations of organochlorines have declined in some cetacean populations as certain countries restricted their production and use (see O'Shea et al., 1999), but in other countries, particularly developing ones, many harmful contaminants continue to be manufactured and used without regard to their potential effects on people and wildlife. Untreated contaminants are openly discharged from the Karnaphuli Paper and Rayon complex at Chandroghona. Pesticides, including some that have been banned in more developed countries are widely used in shoreline agriculture. Organochlorines contained in pesticides and industrial chemicals can bioaccumulate over the lifetime of individuals and from one generation to the next, via nursing and transfer across the placenta, to levels disastrous for the long-term survival of dolphins (O'Shea et al., 1999). A study of shushuks in the Ganges River found that the residue levels of organochlorines were high and that the dolphins had a lower capacity to metabolize organochlorines compared with small marine cetaceans (Kannan et al., 1993, 1994). River dolphins probably also face a greater risk from environmental contamination because their habitat in counter-currents is often located at pollution discharge sites (Kannan et al., 1994) and the hydraulics of these areas may inhibit the dispersal of pollutants.

Collisions with large and small vessels in the congested Chittagong Port may be a source of shushuk mortality, especially during calving and nursing periods when the dolphins' ability to evade boats is compromised. The size of the port and the number of mechanized vessels are likely to increase as the economy of Bangladesh develops. A shushuk was reported struck and killed by a large cargo vessel in the Brahmaputra River near India-Bangladesh border (Mohan, 1996).

\section{Conservation}

A potentially viable population of shushuks is now known to occur in the Karnaphuli-Sangu complex. Although we have no proof of demographic interaction between shushuks in the Karnaphuli-Sangu and Ganges-Brahmaputra-Meghna systems, our findings provide evidence that supports the possibility. Dispersal between these systems does not imply, however, that the species can be considered a single evolutionary unit (see Dizon et al., 1992). Even with substantial interchange of individuals, genetic differences between 
populations can be considerably different because of selection and genetic drift (Slatkin, 1987).

We reiterate the suggestion in Smith et al. (1998) that freshwater dolphins in Bangladesh deserve conservation attention not because they are in immediate danger of extinction but because they still occur in sufficient numbers for early conservation efforts to be effective. In contrast to encouraging results of dolphin surveys in the Karnaphuli-Sangu complex, the negative results of our surveys in Kaptai Lake should be considered a warning to resource managers about the ability of river dolphins to adapt to the lacustrine conditions of a reservoir environment.

\section{Conservation recommendations}

Balancing the needs of wildlife and human beings is a difficult task and this applies particularly to river dolphins that share freshwater resources with one of the world's most densely populated and economically impoverished human populations. Nevertheless, we believe that the environmental requirements of river dolphins reflect the survival needs of local people - a sufficient supply of reasonably unpolluted freshwater and a sustainable source of high quality food - and that this linkage should be used as a basis for implementing effective conservation.

We suggest that the following initiatives, listed in rough order of priority, be taken to protect the long-term viability of the Karnaphuli-Sangu dolphin population.

1 A protected area for shushuks be established in the Sangu River below the Dohazari Bridge. Establishing meaningful protection for dolphins will require implementing a conservation plan that has the support of local people and government officials. A 'managed resource protected area' (IUCN, 1994) where local communities manage fisheries for sustainable use might be supported by local people and therefore viable in the long term, if adequate protection for river dolphins and their prey can be assured (see Smith \& Reeves, 2000a). The most important step would be to reduce sources of accidental killing in gillnets and protect fish populations by restricting or eliminating the use of non-selective fishing gear (monofilament gill- and mosquito nets) and promoting more traditional techniques (hook and line, and throw and lift nets).

2 An awareness programme be initiated to educate local people and government officials on the importance of conserving river dolphins and maintaining sustainable fisheries. The programme should use popular media, such as video, posters, comic books, radio and street theatre; be interactive and respectful of local values and traditions; and involve local university students as environmental educators.
3 Water quality be investigated and monitored on a regular basis. Special emphasis should be paid to persistent contaminants, particularly organochlorines such as polychlorobiphenyl (PCB) and dichlorodiphenyltrichloroethane (DDT). Dolphin blubber and liver samples obtained from strandings or accidental kills can be used to assess the types, levels and health effects of contaminants passed through the riverine food chain. With clean stainless steel instruments, a large sample of blubber (e.g. $10 \times 10 \mathrm{~cm}$ ) should be collected from the mid-thoracic area and a small sample of liver collected from the left lobe (Geraci \& Lounsbury, 1993; Clausen, 1999). Ideally, the samples would be immediately placed on ice in a Teflon-coated plastic bag for transport and then stored in a freezer at $-70{ }^{\circ} \mathrm{C}$ (Geraci \& Lounsbury, 1993). If a freezer is not available, the samples should be stored in a sterilized glass jar with a piece of aluminium foil placed between the lid and sample, and kept in a cool place (P.J.H. Reijnders, pers. comm.).

4 The abundance and habitat of shushuks be monitored on a regular basis using standardized techniques. Longterm monitoring is required to detect population trends and to assess habitat changes caused by human activities. Comparisons of relative abundance and habitat use should be made only among standardized surveys conducted during similar river flow and tidal stages, preferably when water levels are at their lowest (see Smith \& Reeves, 2000b). Surveys conducted during different flow and tidal conditions would be useful, however, for understanding how shushuks use habitat during different flow and salinity conditions. Detailed monitoring of a few selected habitat sites could involve systematic studies of food availability (catch-per-unit effort for fish and crustaceans), human activities (fishing, transport, industry, agriculture, etc.), and physical (morphology, salinity and current speed and distribution) and biological (productivity, and indices of fish and benthic invertebrate diversity) conditions. A population and habitat monitoring programme should involve students from Chittagong University and rangers from the Bangladesh Forest Department and entail a strong training component conducted prior to survey activities. 5 An investigation be conducted on demographic interaction between shushuk populations in the Ganges-Brahmaputra-Meghna and Karnaphuli-Sangu river systems. The study should combine information on shushuk genetics and morphology. For genetic studies, a small piece of skin should be collected from recovered carcasses and stored in a glass or plastic vial filled with 20 per cent dimethyl sulphoxide (DMSO) and saturated sodium chloride. Storage vials should be clearly labelled with the collection date and location, sex if known, and name of the collector. Cross-contamination must be avoided by using sterilized instruments only (i.e. 
washed in soapy water and rinsed in ethanol). In decreasing order of usefulness dried skin, teeth and bones can also be used. A small sample of these should be collected and kept dry individually, in clean plastic bags (Rosel \& Reeves, 2000). For morphological studies, standard measurements of available carcasses and skeletal materials should be taken, ideally by a single researcher in order to reduce variability. Information from bioacoustics, organochlorine levels, parasite species, and perhaps telemetry studies can also be used (Smith \& Reeves, 2000a; Appendix 6). Expertise for conducting these studies is available through the IUCN Species Survival Commission's Cetacean Specialist Group. Although some analyses may have to be conducted outside Bangladesh, close collaboration should be maintained with local scientists.

\section{Acknowledgements}

This investigation would not have been possible without the financial support from the Ocean Park Conservation Foundation and the Whale and Dolphin Conservation Society. Special thanks are given to Thomas Jefferson for championing the project and to Carmen Lor and Josephine Woo and Alison Smith for organizing the funds. We would also like to thank the numerous boatmen who assisted us during the surveys and Dr Irshad Kamal Khan and Dr Shafique Haider Chowdhury for lending us their e-mail facilities. Appreciation is given to Manmatha Nath Sarker for helping us arrange boats and lodging when we were in Cox's Bazaar. Dr Farid Ahsan, Ripon Chakma, Abdul Hannan and Kamrul Hasan are gratefully acknowledged for their assistance with fieldwork. We thank Dr William Perrin and an anonymous reviewer for their useful comments on the manuscript.

\section{References}

Ahmed, B. (2000) Water development and the status of the shushuk (Platanista Gangetica) in Southeast Bangladesh. In Biology and Conservation of Freshwater Cetaceans in Asia, Occasional Papers of the IUCN Species Survival Commission no. 23 (eds R. R. Reeves, B. D. Smith and T. Kasuya), pp. 62-66. IUCN, Gland, Switzerland.

Anderson, J. (1879) Anatomical and Zoological Researches: Comprising an Account of the Zoological Results of the Two Expeditions to Western Yunnan in 1868 and 1875; and a Monograph of the Two Cetacean Genera Platanista and Orcaella. Quaritch, London.

Bangladesh Water Development Board (1994) Northeast Regional Water Management Project (FAP 6), Fisheries Specialist Study. Unpublished report, BWDB, Dhaka.

Clausen, B. (1999) Practical guidelines for postmortem examination and tissue sampling of cetaceans for ecotoxicological purposes. In Chemical Pollutants and Cetaceans (eds P. J. H.
Reijnders, A. Aguilar and G. P. Donovan), pp. 43-46. IWC, Cambridge, UK.

Dizon, A.E., Lockyer, C., Perrin, W.F., DeMaster, D.P. \& Sisson, J. (1992) Rethinking the stock concept: a phylogeographic approach. Conservation Biology, 6, 24-36.

Frissel, C.A., Liss. W.J., Warren, C.E. \& Hurley, M.D. (1986) A hierarchical framework for stream habitat classification: viewing streams in a watershed context. Environmental Management, 10, 199-214.

Geraci, J.R. \& Lounsbury, V.J. (1993). Marine Mammals Ashore: a Field Guide for Strandings. Texas A \& M Sea Grant Publication, Galveston, Texas.

IUCN (1994) Guidelines for Protected Area Management Categories. IUCN Commission on National Parks with assistance of the World Conservation Monitoring Centre, IUCN, Gland, Switzerland.

IUCN (1996) 1996 IUCN Red List of Threatened Animals. IUCN, Gland, Switzerland.

Kannan, K., Sinha, R.K., Tanabe, S., Ichihashi, H. \& Tatsukawa, R. (1993) Heavy metals and organochlorine residues in Ganges river dolphins from India. Marine Pollution Bulletin, 26, 159-162.

Kannan, K., Tanabe, S., Tatsukawa, R. \& Sinha, R.K. (1994) Biodegradation capacity and residue pattern of organochlorine in the Ganges river dolphins from India. Toxicological and Environmental Chemistry, 42, 249-261.

Kellerhalls, R. \& Church, M. (1989) The morphology of large rivers: characterization and management. In Proceedings of the International Large River Symposium, Vol 106 (ed. D. P. Dodge), pp. 31-48. Canadian Special Publications and Aquatic Sciences, Ottawa, Canada.

Mohan, R.S.L. (1996) Rivdolphinews (Newsletter of the Ganges River Dolphin Protection Committee), 1, 1-10.

Mohan, R.S., Dey, S.C., Bairagi, S.P. \& Roy, S. (1997) On a survey of the Ganges river dolphin Platanista gangetica of Brahmaputra River, Assam. Journal of the Bombay Natural History Society, 94, 483-495.

Mohan, R.S., Dey, S.C. \& Bairagi, S.P. (1998) On a resident population of the Ganges river dolphin Platanista gangetica in the Kulsi River (Assam), a tributary of Brahmaputra. Journal of the Bombay Natural History Society, 95, 1-7.

Motwani, M.P. \& Srivastava, C.B. (1961) A special method of fishing for Clupisoma garua (Hamilton) in the Ganges river system. Journal of the Bombay Natural History Society, 58, 285-286.

O'Shea, T.J., Reeves, R.R. \& Long, A.K. (eds) (1999) Marine Mammals and Persistent Ocean Contaminants. Proceedings of the Marine Mammal Commission Workshop Keystone, Colorado, 12-15 October 1998. Marine Mammal Commission, Bethesda, Maryland.

Pelletier, C. \& Pelletier, F.X. (1986) Le Plataniste du Gange. Bhulan, dauphin sacre. L'univers Du Vivant, 8, 8-18.

Reeves, R.R. \& Brownell, R.L. Jr (1989) Susu Platanista gangetica (Roxburgh, 1801) and Platanista minor Owen, 1853. In Handbook of Marine Mammals, Vol 4 (eds S. H. Ridgeway and R. Harrison), pp. 69-99. Academic Press, London.

Reeves, R.R. \& Leatherwood, S. (1995) Report of the First Meeting of the Asian River Dolphin Committee, Ocean Park, Hong Kong. 5-7 December 1994. Ocean Park Conservation Foundation, Hong Kong. 
Reeves, R.R., Leatherwood, S. \& Mohan, R.S.L. (1993) Report from the Seminar on the Conservation of River Dolphins of The Indian Sub-Continent. 18-19 August 1992, New Delhi, India, Whale and Dolphin Conservation Society, Bath, UK.

Rosel, P.E. \& Reeves, R.R. (2000) Genetic and demographic considerations for the conservation of Asian river cetaceans. In Biology and Conservation of Freshwater Cetaceans in Asia, Occasional Papers of the IUCN Species Survival Commission no. 23 (eds R. R. Reeves, B. D. Smith and T. Kasuya), pp. 144152. IUCN, Gland, Switzerland.

Sinha, R.K., Smith, B.D., Sharma, G., Prasad, K., Choudhury, B.C., Sapkota, K., Sharma, R.K. \& Behera, S.K. (2000) Status and distribution of the Ganges susu. Platanista Gangetica, in the Ganges river system of India and Nepal. In Biology and Conservation of Freshwater Cetaceans in Asia, Occasional Papers of the IUCN Species Survival Commission no. 23 (eds R. R. Reeves, B. D. Smith and T. Kasuya), pp. 54-61. IUCN, Gland, Switzerland.

Slatkin, M. (1987) Gene flow and geographic structure of natural populations. Science, 236, 787-792.

Smith, B.D. (1993) 1990 status and conservation of the Ganges river dolphin (Platanista gangetica) in the Karnali River, Nepal. Biological Conservation, 66, 159-170.

Smith, B.D., Haque, A.K.M., Hossain, M.S. \& Khan, A. (1998) River dolphins in Bangladesh: conservation and the effects of water development. Environmental Management, 22, 323-335.

Smith, B.D. \& Reeves, R.R. (2000a) Report of the Second Meeting of the Asian River Dolphin Committee, 22-24 February 1997, Rajendrapur, Bangladesh. In Biology and Conservation of Freshwater Cetaceans in Asia, Occasional Papers of the IUCN Species Survival Commission no. 23 (eds R. R. Reeves, B. D. Smith and T. Kasuya), pp. 1-14. IUCN, Gland, Switzerland.

Smith, B.D. \& Reeves, R.R. (2000b) Survey methods for population assessment of Asian river dolphins. In Biology and Conservation of Freshwater Cetaceans in Asia, Occasional Papers of the IUCN Species Survival Commission no. 23 (eds R. R. Reeves, B. D. Smith and T. Kasuya), pp. 97-115. IUCN, Gland, Switzerland.

Smith, B.D. \& Reeves, R.R. (2000c) Report of the workshop on the effects of water development on river cetaceans in Asia, Rajendrapur, Bangladesh, 26-28 February 1997. In Biology and Conservation of Freshwater Cetaceans in Asia, Occasional Papers of the IUCN Species Survival Commission no. 23 (eds R. R. Reeves, B. D. Smith and T. Kasuya), pp. 15-22. IUCN, Gland, Switzerland.
Smith, B.D., Sinha, R.K., Zhou, K. et al. (2000) Register of water development projects affecting Asian river cetaceans. In Biology and Conservation of Freshwater Cetaceans in Asia, Occasional Papers of the IUCN Species Survival Commission no. 23 (eds R. R. Reeves, B. D. Smith and T. Kasuya), pp. 22-39. IUCN, Gland, Switzerland.

Taylor, B.L. \& Gerrodette, T. (1993) The uses of statistical power in conservation biology: the vaquita and northern spotted owl. Conservation Biology, 7, 439-500.

\section{Biographical sketches}

Brian D. Smith is Asia Coordinator for the IUCN Species Survival Commission Cetacean Specialist Group and the Whale and Dolphin Conservation Society. He has conducted research on marine and freshwater cetaceans in Asia since 1990 and has published papers on his work in Nepal, India, Bangladesh, Vietnam and Myanmar. He recently co-edited a special volume on marine mammals for Asian Marine Biology and a volume on the biology and conservation of freshwater cetaceans in Asia for the IUCN Species Survival Commission Occasional Papers Series.

Benazir Ahmed is Professor of Zoology at the University of Chittagong. He has been teaching and conducting research on fisheries and wildlife in Bangladesh for over 25 years. River dolphins have been the primary focus of his interest for the last 10 years and he is a member of the Asian River Dolphin Committee.

Muhammad Edrise Ali is a lecturer in chemistry at Chittagong College. He has conducted research on the environmental chemistry of rivers in south-east Bangladesh for the last 10 years and been involved in river dolphin research for the last 3 years. He is a member of the Royal Society of Chemistry, UK.

Gill Braulik has been conducting marine mammal research in Hong Kong since 1996 and has been the project coordinator for two large marine mammal research projects in Hong Kong, one focused on Indo-Pacific humpbacked dolphins and the other on finless porpoises. She has conducted surveys, participated in workshops and assisted with training courses in Pakistan, USA, Vietnam, China, Singapore, Indonesia, Bangladesh and Hong Kong. 